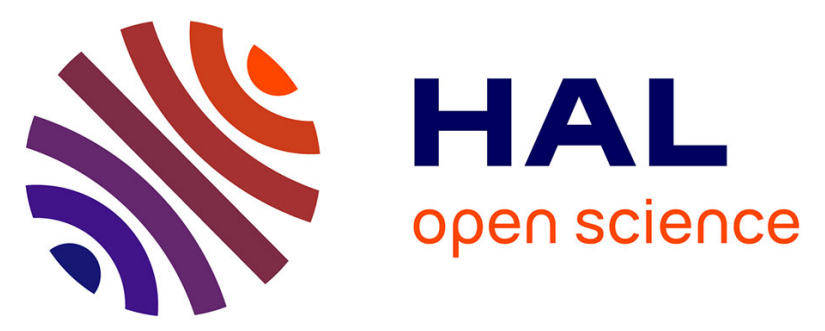

\title{
Diurnal and nocturnal distribution of stratospheric NO: from solar and stellar occultation measurements in the Arctic vortex' Comparison with models and ILAS satellite measurements
}

Sébastien Payan, Claude Camy-Peyret, P. Jeseck, T. Hawat, Michel Pirre, Jean-Baptiste Renard, Claude Robert, Franck Lefèvre, H. Kanzawa, Y. Sasano

\section{To cite this version:}

Sébastien Payan, Claude Camy-Peyret, P. Jeseck, T. Hawat, Michel Pirre, et al.. Diurnal and nocturnal distribution of stratospheric NO: from solar and stellar occultation measurements in the Arctic vortex' Comparison with models and ILAS satellite measurements. Journal of Geophysical Research: Atmospheres, 1999, 104 (D17), pp.585 - 606. 10.1029/1999JD900276 . insu-02879231

\section{HAL Id: insu-02879231 \\ https://hal-insu.archives-ouvertes.fr/insu-02879231}

Submitted on 23 Jun 2020

HAL is a multi-disciplinary open access archive for the deposit and dissemination of scientific research documents, whether they are published or not. The documents may come from teaching and research institutions in France or abroad, or from public or private research centers.
L'archive ouverte pluridisciplinaire HAL, est destinée au dépôt et à la diffusion de documents scientifiques de niveau recherche, publiés ou non, émanant des établissements d'enseignement et de recherche français ou étrangers, des laboratoires publics ou privés. 


\title{
Diurnal and nocturnal distribution of stratospheric $\mathrm{NO}_{2}$ from solar and stellar occultation measurements in the Arctic vortex: Comparison with models and ILAS satellite measurements
}

\author{
S. Payan, ${ }^{1}$ C. Camy-Peyret, ${ }^{1}$ P. Jeseck, ${ }^{1}$ T. Hawat, ${ }^{1,2}$ M. Pirre, ${ }^{3,4}$ J.-B. Renard, ${ }^{3}$ \\ C. Robert, ${ }^{3}$ F. Lefèvre, ${ }^{5,6}$ H. Kanzawa, ${ }^{7}$ and Y. Sasano ${ }^{7}$
}

\begin{abstract}
NO}_{2}$ mixing ratio profiles were measured at sunset between 14 and $30 \mathrm{~km}$ using the Limb Profile Monitor of the Atmosphere (LPMA) experiment and during the night between 13 and $31 \mathrm{~km}$ using the Absorption par Minoritaires Ozone et $\mathrm{NO}_{x}(\mathrm{AMON})$ experiment inside the Arctic vortex, both on February 26, 1997. Coinciding profiles measured by the Improved Limb Atmospheric Spectrometer (ILAS) instrument on board ADEOS have been used to check the consistency between the satellite and balloon profiles for $\mathrm{NO}_{2}, \mathrm{O}_{3}$, and $\mathrm{HNO}_{3}$. A box model has been used for the photochemical correction of the LPMA NO${ }_{2}$ profiles at sunset. The resulting $\mathrm{NO}_{2}$ balloon-borne profiles of LPMA and AMON are compared to each other after accounting for the day/night photochemical variation using the box model initialized with measurements. The comparisons thus performed show an average difference less than $9 \%$ between the two measurements (considered to sample similar air masses) when the box model is initialized with little chlorine activation (i.e., when the major burden of chlorine is stored in $\mathrm{ClONO}_{2}$ ) for a 1 day integration. The comparison with the Reprobus 3-D chemistry transport model (CTM) seasonal simulations clearly confirms an underestimation of $\mathrm{NO}_{2}$ by the model below $25 \mathrm{~km}$, in the altitude range where aerosols lead to a complete removal of $\mathrm{NO}_{\mathrm{x}}$ in the model. Recent updates of rate coefficients for conversion of $\mathrm{HNO}_{3}$ into $\mathrm{NO}_{2}$ only slightly improve the $\mathrm{NO}_{2}$ model results in vortex conditions. These results suggest that a source of $\mathrm{NO}_{2}$ is still lacking in the CTM.
\end{abstract}

\section{Introduction}

$\mathrm{NO}_{2}$ plays an important role in the lower stratosphere because it is involved both in chemical processes leading to ozone destruction and in processes buffering chlorine activation through the formation of the mixed reservoir $\mathrm{ClONO}_{2}[$ Brasseur and Solomon, 1986]. Previous measurements at midlatitudes, for air unaffected by polar stratospheric clouds but under different

\footnotetext{
${ }^{1}$ Laboratoire de Physıque Moléculaire et Applications, Université P. et M. Curie, Paris, France.

${ }^{2}$ Now at University of Balamand, Faculty of Engineerng, Beinut, Lebanon

${ }^{3}$ Laboratorre de Physique et de Chimie de l'Envronnement, CNRS, Orléans, France.

${ }^{4}$ Also at Université d'Orléans, Orléans, France.

${ }^{3}$ Centre National de Recherche Météorologique, Météo-France/CNRS, Toulouse, France.

Gow at Service d'Aéronomie du CNRS, Université P. et M. Curie, Paris, France.

Natronal Institute for Environmental Studies, Tsukuba, Japan.
}

Copyright 1999 by the American Geophysical Union.

Paper number $1999 \mathrm{JD} 900276$.

0148-0227/99/1999JD900276\$09.00 aerosol loading conditions [Sen et al., 1998; Kondo et al., 1997; Webster et al., 1994] have suggested an incomplete understanding of the factors regulating the $\mathrm{NO}_{2}$ concentration below $30 \mathrm{~km}$. In winter conditions, measurements of $\mathrm{NO}_{2}$ inside the Arctic polar vortex [Lary et al., 1997; Wetzel et al., 1997] show a disagreement with three-dimensional (3-D) chemistry transport model simulations in the lower stratosphere below 22 $\mathrm{km}$ altitude. Measurements of $\mathrm{NO}_{2}$ profiles in the polar vortex are not easily performed, however, and the available database [Glatthor et al., 1998; Newchurch et al., 1996] does not provide an adequate sampling of the photochemical cycle.

In order to complement previous observations and to document the observed disagreement, we present new measurements of the $\mathrm{NO}_{2}$ vertical profiles inside the polar Arctic voriex at the same location but for different times of the diurnal/nocturnal cycle. Indeed, for the first time, $\mathrm{NO}_{2}$ profile measurements have been performed during the day (late afternoon and sunset) and 5 hours later during the night using respectively the balloon-borne instruments Limb Profile Monitor of the Atmosphere (LPMA) and Absorption par Minoritaires Ozone et $\mathrm{NO}_{\mathrm{x}}$ (AMON), in the framework of the Improved Limb Atmospheric Spectrometer (ILAS) validation balloon campaign in February 1997 [Kanzawa et al., 1997] from Kiruna, Sweden $\left(68^{\circ} \mathrm{N}, 21^{\circ} \mathrm{E}\right)$. AMON measurements of $\mathrm{O}_{3}$; LPMA measurements of $\mathrm{O}_{3}, \mathrm{HCl}$, and $\mathrm{HNO}_{3}$; and ILAS [Sasano et al., 1999] measurements of $\mathrm{NO}_{2}, \mathrm{O}_{3}$ and $\mathrm{HNO}_{3}$ obtained for February 26, 1997, are also presented. 


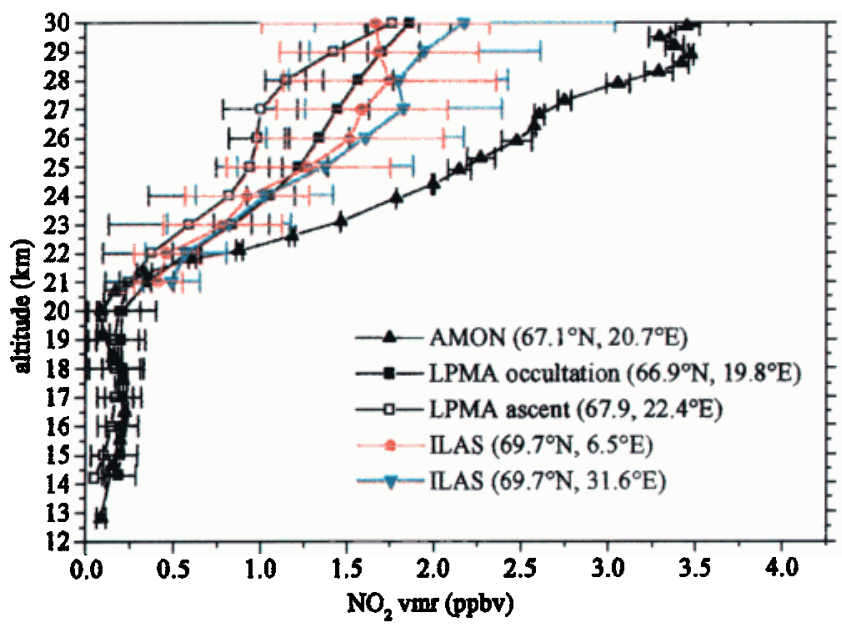

Plate 1. $\mathrm{NO}_{2}$ vertical profiles on February 26, 1997, retrieved from ILAS satellite measurements (red circles and blue inverted triangles), LPMA ascent measurements (white boxes), LPMA occultation measurements (black boxes), and AMON nighttime measurements (black triangles). The LPMA measurements are photochemically corrected $\left(\mathrm{SZA}=83^{\circ}\right.$ for ascent, $\mathrm{SZA}=90^{\circ}$ for occultation).

$\mathrm{NO}_{2}, \mathrm{O}_{3}, \mathrm{HCl}$, and $\mathrm{HNO}_{3}$ measurements are compared with the output of the Reprobus 3-D chemistry transport model (CTM) [Lefevre et al., 1998] and with the output of a box model constrained with measurements of AMON and LPMA. The box model output has also been used for intercomparison of the LPMA and AMON $\mathrm{NO}_{2}$ profiles and for the photochemical correction of the LPMA profiles. The results are discussed in terms of nitrogen and chlorine partitioning. The effect of recent updates of rate coefficients for gas-phase conversion of $\mathrm{HNO}_{3}$ into $\mathrm{NO}_{2}$ has been considered.

\section{Observation Methods and Vertical Profiles}

As a remarkable achievement of the Centre National d'Etudes Spatiales (CNES) launching team, the two flights reported here took place in the late afternoon and the early night of February 26, 1997, from the Swedish launching base of the European

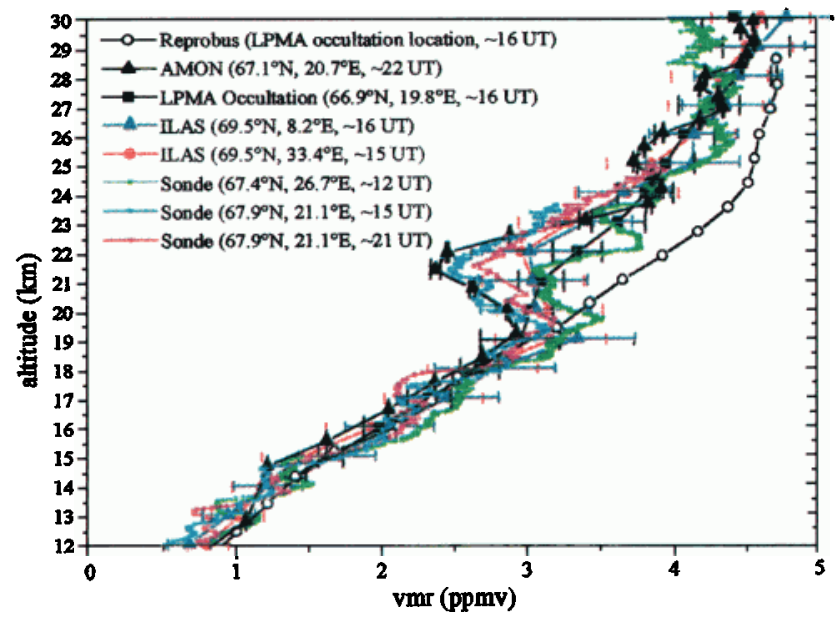

Plate 2. Vertical profiles of $\mathrm{O}_{3}$ measured by LPMA (black boxes), AMON (black triangles), soundings (green, magenta, and cyan boxes), and ILAS (blue triangles and red circles) compared to Reprobus CTM modeling.

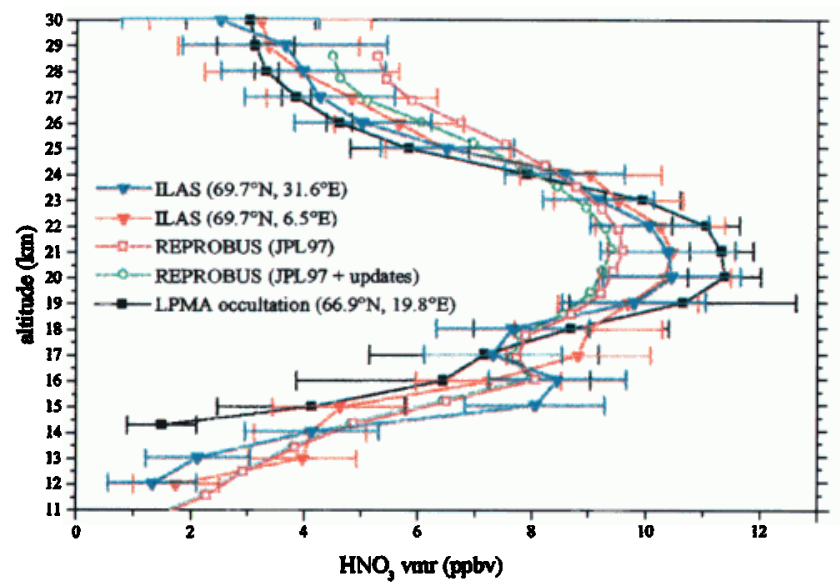

Plate 3. LPMA $\mathrm{HNO}_{3}$ occultation measurements, corresponding Reprobus modeling with JPL97 and with updated rate constants, and ILAS measurements for February 26, 1997.

Space Research Range (ESRANGE) $\left(\sim 68^{\circ} \mathrm{N}, \sim 21^{\circ} \mathrm{E}\right)$. The LPMA experiment has collected infrared spectra in the late afternoon for increasing solar zenith angles (SZA) from 1330 UT to 1459 UT during ascent (SZA $<90^{\circ}$ ) and from 1500 UT to $1540 \mathrm{UT}$ during occultation $\left(\mathrm{SZA}>90^{\circ}\right.$ ). The AMON experiment collected UV-visible spectra during the night from 2105 UT to 2211 UT. Two measurements were performed by ILAS rather close to Kiruna (around $500 \mathrm{~km}$ ) on the same day at 1426 and 1607 UT. The LPMA and AMON NO${ }_{2}$ vertical profiles retrieved during the two flights of February 26 for the corresponding time periods are presented in Plate 1 together with the coincident ILAS measurements. The different measurements are described below.

\subsection{LPMA Óbservations}

The LPMA is a remote sensing infrared Fourier transform instrument operating in absorption against the Sun [CamyPeyret, 1995]. With its high spectral resolution and sensitivity, the retrieval of vertical profiles of trace species having stratospheric mixing ratios as small as $0.1 \mathrm{ppbv}$ is possible. During the flight, the Sun was encountered above a rather elevated cloud deck at about $10 \mathrm{~km}$. The first complete interferograms (after proper setting of the gains of the preamps for each channel) were obtained just above $13 \mathrm{~km}$. From that point on, the primary pointing system, the heliostat, the interferometer, and all the ancillary equipment performed nominally during ascent, float, and occultation up to loss of Sun, again behind the high cloud cover $(\sim 13 \mathrm{~km})$. The 170 recorded spectra show sufficient absorption by $\mathrm{NO}_{2}$ for precise retrieval in the appropriate micro-window around $2914.6 \mathrm{~cm}^{-1}$. The LPMA flight observations started at 1330 UT (the balloon was at an altitude of $14.2 \mathrm{~km}$ during its ascent), the float was reached at 1500 UT and occultation measurements (SZA $>90^{\circ}$ ) were recorded until loss of Sun at $1540 \mathrm{UT}$. Around 120 spectra were recorded during ascent (SZA $<90^{\circ}$ ), and around 50 during occultation. Tables $1 \mathrm{a}$ and $1 \mathrm{~b}$ give the altitude, location, and time (UT) for a few representative spectra recorded during ascent and during occultation, respectively.

A global fit algorithm [Carlotti, 1988] associated with an efficient minimization algorithm of the Levenberg-Marquardt type [Press et al., 1992] is used for the retrieval. This retrieval algorithm [Payan et al., 1998] allows us to retrieve vertical profiles from both ascent and occultation data. The retrieval from 
Table 1a. Latitude (Degrees North), Longitude (Degrees East), Solar Zenith Angle (SZA), Time, and Local Time of LPMA Ascent Measurements for Selected Balloon Atitudes $\mathbf{z}$

\begin{tabular}{lccccc}
\hline Latitude & Longitude & SZA, deg & Time, UT & $\begin{array}{c}\text { Local Time } \\
\text { hours }\end{array}$ & Z, km \\
\hline 67.90 & 21.66 & 81.76 & 1330 & 1500 & 14.20 \\
67.94 & 22.23 & 82.94 & 1345 & 1515 & 18.98 \\
67.97 & 22.92 & 84.01 & 1357 & 1527 & 22.98 \\
67.98 & 2377 & 85.17 & 1410 & 1540 & 26.60 \\
67.97 & 24.63 & 86.39 & 1423 & 1553 & 29.50 \\
67.90 & 2677 & 89.76 & 1456 & 1626 & 31.86 \\
\hline
\end{tabular}

ascent data is only possible when using a global fit method because the spectral information is strongly integrated along the verticai in the ascent spectra. In all cases the molecular parameters used in the forward model are extracted from the HITRAN96 database. Because of the different viewing geometries for ascent and occultation spectra and because of the inhomogeneities in the geophysical fields inside and around the Arctic vortex, we have decided to perform separate retrievals for the two geometries. The volume mixing ratio profiles (together with the corresponding error) have been retrieved from the selected lowest observation points $(14.2 \mathrm{~km}$ for ascent and 14.3 $\mathrm{km}$ for occultation, with volume mixing ratio (vmr) values at these levels extrapolated from values at the two higher retrieval altitudes) up to the highest balloon altitude (float at $30 \mathrm{~km}$ ) with a vertical sampling of $1 \mathrm{~km}$.

The rapid time variation in the concentration of $\mathrm{NO}_{2}$ at sunset, if not properly accounted for, will produce errors in the retrieval of this species from solar occultation measurements [Kerr et al., 1987; Russel et al., 1988; Newchurch et al., 1996]. The variation of $\mathrm{NO}_{2}$ is mainly governed by the reaction of $\mathrm{NO}$ with $\mathrm{O}_{3}$, the reaction of $\mathrm{NO}_{2}$ with $\mathrm{ClO}$, and by the photolysis of $\mathrm{NO}_{2}$. Hence accurate knowledge of the local values of $\mathrm{O}_{3}$, temperature, and radiation field is required to calculate the variation of $\mathrm{NO}_{2}$ along the occultation line of sight. The vertical profile of $\mathrm{O}_{3}$ has been measured by the AMON and the LPMA experiments. These measurements are presented in Plate 2 together with three soundings performed the same day. The measurements are in good agreement below $19 \mathrm{~km}$ and above $23 \mathrm{~km}$ (differences less than $10 \%$ ), whereas some differences are observed between 19 and $23 \mathrm{~km}$. The AMON profile and the soundings performed from Kiruna show more structure than the LPMA profile or the sounding performed from Sodankyla (Finland). Taking into account the locations and the times of each measurement, these differences in a rather narrow altitude range are probably due to small-scale geophysical variability (proximity of the vortex edge, leewaves, transport).

We have used the LPCE time-dependent photochemical box model [Ramaroson et al., 1992; Renard et al., 1996] to calculate the diurnal variation of $\mathrm{NO}_{2}$. The model has been constrained with the AMON measurements of $\mathrm{NO}_{2}$, and the LPMA measurements of $\mathrm{O}_{3}, \mathrm{HCl}, \mathrm{H}_{2} \mathrm{O}, \mathrm{N}_{2} \mathrm{O}, \mathrm{CH}_{4}$, and $\mathrm{HNO}_{3}$. Although simultaneous observations of $\mathrm{HCl}$ and $\mathrm{ClONO}_{2}$ have been performed previously with the LPMA instrument [Payan et al., 1998], the loss (during ground testing) of a $\mathrm{KCl}$ beamsplitter (replaced by a $\mathrm{CaF}_{2}$ one) unfortunately prevented us from covering the $780 \mathrm{~cm}^{-1}$ feature of $\mathrm{ClONO}_{2}$ which was not available for constraining the box model. The accuracy with which the model calculates the relative variation of $\mathrm{NO}_{2}$ is a critical element for correcting solar-occultation retrievals. We have used the box model to describe the altitude dependent diurnal variation of $\mathrm{NO}_{2}$ relative to two reference values, $\mathrm{SZA}=83^{\circ}$ for ascent (corresponding to $20 \mathrm{~km}$ altitude) and $\mathrm{SZA}=90^{\circ}$ for occultation measurements. Box model derived correcting factors have been used in the LPMA global fit retrieval algorithm to correct the $\mathrm{NO}_{2} \mathrm{vmr}$ at each layer boundaries for each line of sight during ascent and on each side of the tangent point along the line of sight for occultation. The vmr differences are less than $6 \%$ at any level as compared to a photochemically noncorrected profile. The resulting $\mathrm{NO}_{2}$ vertical profiles (ascent and occultation) are thus corresponding to the chosen reference solar zenith angles (of $83^{\circ}$ for ascent and $90^{\circ}$ for occultation) for each altitude.

\subsection{AMON Observations}

AMON is composed of a $20-\mathrm{cm}$ Cassegrain telescope with a $1-m$ focal length, a grating spectrometer designed for continuous coverage of the UV and visible wavelength domains, and a CCD detector 385 by 578 pixels [Robert, 1992; Naudet et al., 1994]. Spectra are sampled in five bands at $0.14 \mathrm{~nm}$ per pixel in four visible bands and $0.18 \mathrm{~nm}$ per pixel in one UV band. During stratospheric flight, the instrument was mounted on board the stabilized platform of Geneva Observatory. Observations were made using the stellar occultation method, which allows retrieval of slant column densities of atmospheric species for different lines of sight below the balloon horizon. An onion-peeling inversion technique is used to derive the vertical distribution of the trace species and the aerosol extinction coefficient.

$\mathrm{NO}_{2}$ absorption was observed by AMON between 400 and $475 \mathrm{~nm}$, where its spectral signature is easily recognized. The slant columns were retrieved by applying a differential method, which allows the Rayleigh, aerosols, and ozone contributions to be removed by high-pass filtering, and by using the $\mathrm{NO}_{2}$ cross sections measured by Harder et al. [1997]. The use of new $\mathrm{NO}_{2}$ low-temperature cross sections (J.P. Burrows et al., private communication, 1998; Web site http://www.iup.physik.unibremen.de/gruppen/molspec.html) will not change the retrieved profile by more than $2 \%$. The ozone contribution was derived from the Chappuis band between 550 and $625 \mathrm{~nm}$ using the $\mathrm{O}_{3}$ cross sections of J. Brion (Reims University, private communication, 1997). A detailed description of the data processing is given by Renard et al. [1996].

The AMON flight observations started at $2105 \mathrm{UT}$ and ended at $2211 \mathrm{UT}$, when the balloon was at float altitude (around $31.4 \mathrm{~km}$ ). The star used for the occultation was Rigel. Around 100 spectra were recorded. Table $1 \mathrm{c}$ gives the altitude, location, and time (UT) for a few representative spectra recorded by AMON.

Table 1b. Latitude (Degrees North), Longitude (Degrees East), Solar Zenith Angle (SZA), Time, and Local Time of LPMA Occultation Measurements for Selected Tangent Atitudes $\mathrm{H}_{t}$

\begin{tabular}{lccccc}
\hline Latitude & Longitude & SZA, deg & Time, UT & $\begin{array}{c}\text { Local Time, } \\
\text { hours }\end{array}$ & $\mathrm{H}_{\mathrm{b}} \mathrm{km}$ \\
\hline 67.85 & 26.77 & 90.10 & $14: 59$ & $15: 29$ & 31.94 \\
67.29 & 23.89 & 91.68 & $15: 13$ & $16: 43$ & 29.16 \\
67.20 & 23.21 & 92.03 & $15: 16$ & $16: 46$ & 27.83 \\
67.01 & 21.51 & 92.94 & $15: 24$ & $16: 54$ & 23.60 \\
66.93 & 20.47 & 93.48 & $15: 28$ & $16: 58$ & 2037 \\
66.89 & 19.44 & 94.03 & $15: 33$ & $17: 03$ & 1681 \\
66.87 & 18.78 & 94.39 & $15: 36$ & $17: 06$ & 14.31 \\
\hline
\end{tabular}


Table 1c. Latitude (Degrees North), Longitude (Degrees East), Time, and Local Time of the nighttime AMON Measurements for Selected Tangent Atitudes $\mathrm{H}_{t}$

\begin{tabular}{ccccc}
\hline Latitude & Longitude & Time, UT & $\begin{array}{c}\text { Local Tme, } \\
\text { hours }\end{array}$ & $\mathrm{H}_{\mathrm{l}, \mathrm{km}}$ \\
\hline 67.73 & 27.29 & $21 \cdot 28$ & $22 \cdot 58$ & 31.38 \\
6745 & 25.48 & $21: 38$ & $23: 08$ & 29.63 \\
6724 & 23.74 & $21: 46$ & $23: 16$ & 26.50 \\
67.14 & 2232 & $21: 53$ & $23: 23$ & 23.10 \\
67.06 & 20.71 & $22: 00$ & $23: 30$ & 18.41 \\
67.01 & 19.82 & 22.03 & $23: 33$ & 15.56 \\
67.00 & 1849 & 22.06 & 2336 & 11.31 \\
\hline
\end{tabular}

\subsection{Geophysical Conditions}

According to the temperature profile encountered during the flight (minimum of $195 \mathrm{~K}$ around $21 \mathrm{~km}$ ), polar stratospheric clouds (PSCs) were not thermodynamically possible (around $3 \mathrm{~K}$ above the Nitric Acid Trihydrate (NAT) threshold temperature). Backward trajectory calculations based on analysis data from the European Centre for Medium-Range Weather Forecasts (ECMWF) indicate that PSC formation was possible 9 days before the flight in air masses passing over Kiruna for the $400 \mathrm{~K}$ potential temperature level (around $16 \mathrm{~km}$ ) and 8 days before the flight for the $550 \mathrm{~K}$ level (around $22 \mathrm{~km}$ ). The low concentrations observed between 19 and $22 \mathrm{~km}$ in the measured $\mathrm{HCl}$ profile (Figure 1) indeed indicate that chlorine activation may have occurred in this altitude range along the trajectories sampled by LPMA, producing a dip in the $\mathrm{HCl}$ profile as a result of the depletion of this species through heterogeneous processes. The fact that the low $\mathrm{HCl}$ values are not associated with low $\mathrm{HF}$ values measured by LPMA during the same flight is an indication that the feature in the $\mathrm{HCl}$ profile is not related to outside vortex intrusion but is potentially related either to mesoscale or to leewave PSCs. Analysis of Total Ozone Mapping Spectrometer (TOMS) and TIROS Operational Vertical Sounder (TOVS) ozone column amounts and analysis of the ECMWF potential vorticity (PV) maps (at 1200,1800 and $000 \mathrm{UT}$ ) indicate that the measurements have been performed in the inner edge of the polar vortex. The LPMA measurements for ascent (reference SZA of $83^{\circ}$ ) have been performed more inside the vortex than those for occultation (reference SZA of $90^{\circ}$ ). A significant part of the differences can be assigned to the $\mathrm{NO}_{2}$ photochemical variation between these two SZA values. But as can be seen from the positions of the tangent points (see Tables $1 \mathrm{~b}$ and $1 \mathrm{c}$ ), the air masses sampled by LPMA during occultation are very close to those sampled 5 hours later by AMON, and within this short time period, the variation in the PV field was only minor. So for $\mathrm{NO}_{2}$, we limit ourselves to the comparison of the occultation LPMA profile which can be directly compared to the $A M O N$ profile, provided the photochemical variation between $\mathrm{SZA}=90^{\circ}$ and the nighttime AMON measurements is properly accounted for by the box model.

\subsection{Comparison With ILAS}

Global measurements from space are necessary to better understand the disagreement between modeling and measurements. The ILAS is a solar occultation satellite sensor developed by the Environment Agency of Japan to monitor and study the stratospheric ozone layer environment by using an infrared grating spectrometer and a visible grating spectrometer [Sasano et al., 1999]. It was launched on board the Advanced Earth Observing Satellite (ADEOS) in August 1996. Continuous measurements in two high northern or southern latitude bands were performed between November 1996 and June 1997. With its infrared spectrometer, ILAS can measure vertical profiles of $\mathrm{O}_{3}, \mathrm{HNO}_{3}, \mathrm{NO}_{2}, \mathrm{~N}_{2} \mathrm{O}, \mathrm{CH}_{4}$, and $\mathrm{H}_{2} \mathrm{O}$. Profiles of aerosol extinction coefficients at four infrared wavelengths are also derived. With its visible spectrometer, covering the molecular oxygen absorption A-band, temperature and pressure profiles are obtained, as well as the aerosol extinction profile at $780 \mathrm{~nm}$. Data processing is based on a nonlinear least squares method for spectral fitting and the onion-peeling method for vertical profiling.

The altitude range for data analysis is from cloud-top to about $60 \mathrm{~km}$, depending on retrieved parameters. The lowest altitude was sometimes limited by insufficient Sun-tracking capability due to very low signal intensity. The measurement region of ILAS was over high-latitude regions $\left(57-73^{\circ} \mathrm{N}\right.$ and $\left.64-88^{\circ} \mathrm{S}\right)$, which changed according to the season. Because of these unique measurement opportunities, ILAS can generate daily heightlongitude cross-sectional maps of atmospheric parameters.

The LPMA and AMON measurements presented in this paper took place in the framework of the ADEOS/ILAS validation balloon campaign carried out from Kiruna (Sweden) in FebruaryMarch 1997. Two measurements were performed by ILAS rather close to Kiruna (around $500 \mathrm{~km}$ ) on February 26, 1997. This instrument uses the solar occultation technique at sunset, so the $\mathrm{NO}_{2}$ ILAS measurements can be directly compared to the LPMA measurements corrected for $\mathrm{SZA}=90^{\circ}$. A comparison of our measurements of $\mathrm{NO}_{2}$ with those of ILAS (algorithm version 3.10) bracketing the LPMA ones is given in Plate 1. The ILAS $\mathrm{NO}_{2}$ vertical profile is given above $21 \mathrm{~km}$. Below that level, the strong correlation between $\mathrm{NO}_{2}$ and aerosol absorption features lead to an overestimation of $\mathrm{NO}_{2}$ values due to improper aerosol absorption modeling in the retrieval. It can be seen that the ILAS error bars generated by the current version of the operational algorithm and discussed by Yokota et al. [1998] are rather large and do not fully warrant a statistically significant comparison with the AMON and LPMA vertical distributions of $\mathrm{NO}_{2}$. If we just consider the retrieved ILAS vmr, a good general agreement (average differences less than $12 \%$ and $11 \%$ for the two ILAS measurements) is found.

In the case of $\mathrm{HNO}_{3}$ (Plate 3), ILAS measurements are in good agreement with LPMA. The average differences are less

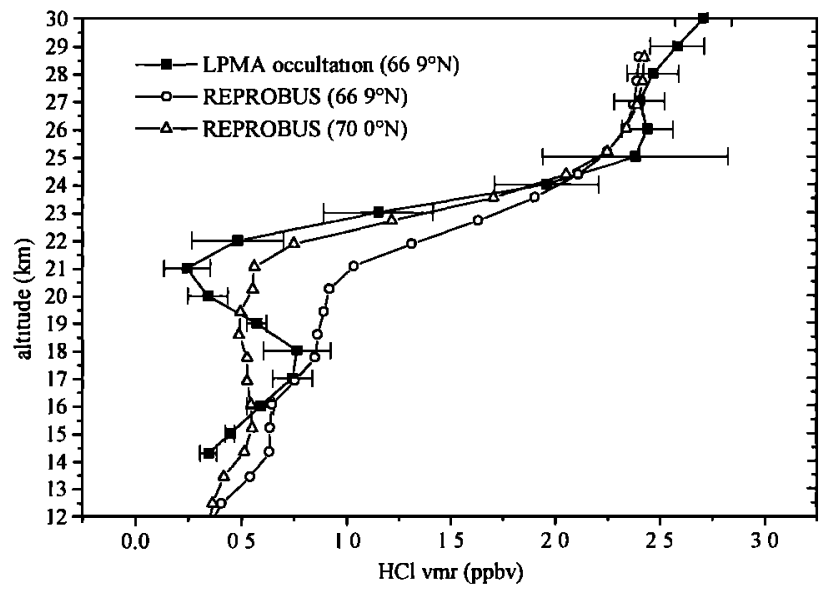

Figure 1. LPMA $\mathrm{HCl}$ profile from occultation measurements compared to Reprobus modeling (February 26, 1997). All longitudes pertain to $19.8^{\circ} \mathrm{E}$. 
than $12 \%$ and $15 \%$ between the LPMA and the two ILAS measurements, respectively. The differences are larger below 17 $\mathrm{km}$. However, the distance between the measurements (around $500 \mathrm{~km}$ ) could explain part of these differences. The ILAS ozone measurements (Plate 2) are overall in good agreement with LPMA measurements and an ozone sounding performed the same day from Sodankyla (differences less than 10\%). The agreement with AMON measurements and the two Kiruna soundings is about the same, but there is some indication of variability in the altitude range $19-23 \mathrm{~km}$ between the two groups of ozone profiles (this may be assigned to small-scale geophysical variability).

\section{Study of the $\mathrm{NO}_{2}$ Diurnal Variations Using a Box Model}

We have used a photochemical box model to study and reproduce realistically the diurnal and nocturnal variation of $\mathrm{NO}_{2}$ as observed by the LPMA and AMON measurements. A 1 day integration has been performed, from February 26 at 000 UT to February 26 at 2330 UT, assuming that no new chlorine activation occurred during this period. The simulations have been performed for the location of the AMON observations, from 14 to $30 \mathrm{~km}$, in 14 boxes separated by $2 \mathrm{~km}$ (between 14 and $20 \mathrm{~km}$ altitude) and by $1 \mathrm{~km}$ (between 20 and $30 \mathrm{~km}$ ). We have assumed that for each altitude the two balloon measurements have been performed in the same air mass (this was confirmed by backward trajectories, PV map, and $\mathrm{O}_{3}$ total column map analyses). This hypothesis is reasonable, taking into account the small distance between the measurement locations especially between the occultation LPMA measurements and the AMON measurements as well as the short time difference (less than 6 hours). The model includes a full chemical system, taking into account species of the $\mathrm{O}_{\mathrm{x}}, \mathrm{HO}_{\mathrm{x}}, \mathrm{NO}_{\mathrm{y}}, \mathrm{ClO}_{\mathrm{y}}$, and $\mathrm{BrO}_{\mathrm{y}}$ families and the long-lived species $\mathrm{N}_{2} \mathrm{O}, \mathrm{CH}_{4}, \mathrm{H}_{2} \mathrm{O}$, and $\mathrm{CO}$. Rate constants and dissociation cross sections (taking into account their temperature dependence) are those extracted from De More et al [1997]. The total concentrations of the $\mathrm{NO}_{y}, \mathrm{ClO}_{\mathrm{y}}$, and $\mathrm{BrO}_{\mathrm{y}}$ families are fixed, as well as the concentrations of the long-lived species.

The $\mathrm{NO}_{2} \mathrm{vmr}$ variation (between the LPMA measurements before or at sunset and the AMON measurements during the night) is mainly governed by the following chemical reactions :

$$
\begin{aligned}
& \mathrm{NO}_{2}+\mathrm{hv} \stackrel{\mathrm{J}_{1}}{\longrightarrow} \mathrm{NO}+\mathrm{O} \\
& \mathrm{NO}+\mathrm{O}_{3} \stackrel{\mathrm{k}_{1}}{\longrightarrow} \mathrm{NO}_{2}+\mathrm{O}_{2} \\
& \mathrm{NO}+\mathrm{ClO} \stackrel{\mathrm{k}_{2}}{\longrightarrow} \mathrm{NO}_{2}+\mathrm{Cl} \\
& \mathrm{NO}_{2}+\mathrm{O}_{3} \stackrel{\mathrm{J}_{1}}{\longrightarrow} \mathrm{NO}_{3}+\mathrm{O}_{2} \\
& \mathrm{NO}_{3}+\mathrm{NO}_{2} \stackrel{\mathrm{M}}{\longrightarrow} \mathrm{N}_{2} \mathrm{O}_{5} \\
& \mathrm{~N}_{2} \mathrm{O}_{5}+\mathrm{hv} \stackrel{\mathrm{J}_{2}}{\longrightarrow} \mathrm{NO}_{3}+\mathrm{NO}_{2} \\
& \mathrm{ClO}+\mathrm{NO}_{2} \stackrel{\mathrm{M}}{\longrightarrow} \mathrm{ClONO}_{2} \\
& \mathrm{ClONO}_{2}+\mathrm{hv} \stackrel{\mathrm{J}_{3}}{\longrightarrow} \mathrm{Cl}+\mathrm{NO}_{3}
\end{aligned}
$$

The first three reactions lead to a fast equilibrium between NO and $\mathrm{NO}_{2}$ during the day:
$\frac{[\mathrm{NO}]}{\left[\mathrm{NO}_{2}\right]}=\frac{\mathrm{J}_{1}}{\mathrm{k}_{2}[\mathrm{ClO}]+\mathrm{k}_{1}\left[\mathrm{O}_{3}\right]}$

During sunset, $\mathrm{NO}$ is quickly converted to $\mathrm{NO}_{2}$. Let us ciefine

$$
\left[\mathrm{NO}_{\mathrm{x}}\right]=[\mathrm{NO}]+\left[\mathrm{NO}_{2}\right]
$$

In the conditions studied in the paper (high SZA. Arctic vortex), the evolution of this sum during the late afternoon is mainly governed by the last two equations (R7) and (R8), which lead to the decrease of $\left[\mathrm{NO}_{x}\right]$ until sunset, while $\mathrm{N}_{2} \mathrm{O}_{5}$ photolysis (R6) has a negligible effect on the $\left[\mathrm{NO}_{\mathrm{x}}\right]$ variation during the day because of the vortex conditions. During the night, reactions (R4) and (R5) become dominant in the variation of this sum for low $\mathrm{ClO}$ concentrations. In the case of high $\mathrm{ClO}$ concentrations, the $\mathrm{ClO}+\mathrm{NO}_{2}$ reaction is dominant and leads to very small values of $\mathrm{NO}_{2}$. Let us define $\left[\mathrm{NO}_{\mathrm{x}}\left(90^{\circ}\right)\right]$ as the $\mathrm{NO}_{\mathrm{x}}$ concentration for $\mathrm{SZA}=90^{\circ}$. Like Flaud et al. [1998], we can show that the $\left[\mathrm{NO}_{\mathrm{x}}\right]$ time variation during the night satisfies the following relation :

$$
\left[\mathrm{NO}_{\mathrm{x}}\right]=\left[\mathrm{NO}_{\mathrm{x}}\left(90^{\circ}\right)\right] \exp \left(-2 \mathrm{k}_{3}\left[\mathrm{O}_{3}\right] \Delta \mathrm{t}\right)
$$

The evolution of $\mathrm{NO}_{2}$ between the times of the measurements is therefore strongly dependent on the $\mathrm{O}_{3}$ concentration, the temperature, and the degree of chlorine activation. The $\mathrm{O}_{3} \mathrm{vmr}$ has been measured by LPMA and AMON, the temperature is known from actual meteorological soundings the day of the flight, and the LPMA HCl measurements allow us to initialize the $\mathrm{ClO}_{\mathrm{y}}$ species defined as $\left[\mathrm{ClO}_{\mathrm{y}}\right]=[\mathrm{ClO}]+2\left[\mathrm{Cl}_{2} \mathrm{O}_{2}\right]+$ $\left[\mathrm{ClONO}_{2}\right]+[\mathrm{HOCl}]+[\mathrm{OClO}]$. We can consider that, with a good approximation, this value is equal to $[\Sigma \mathrm{Cl}]-[\mathrm{HCl}]-\left[\mathrm{Cl}_{\mathrm{org}}\right]$, where $[\Sigma \mathrm{Cl}]$ is the total stratospheric chlorine burden and $\left[\mathrm{Cl}_{\text {org }}\right]$ is the total organic chlorine (source species). These latter values have been taken from the Reprobus CTM (discussed in the next section) for the corresponding day of the measurements. The partitioning has been chosen so that the box model reproduces reasonably well the LPMA and AMON measurements.

The box model was first initialized with the chlorine partitioning given by Reprobus. But below $25 \mathrm{~km}$ the box model $\mathrm{NO}_{2} \mathrm{vmr}$ was smaller than the measurements and was very similar to Reprobus results. Several sets of chlorine partitioning were then tested, $\mathrm{HCl}$ being initialized with LPMA measurements. The best agreement is obtained when values of $\mathrm{ClO}$ and $\mathrm{Cl}_{2} \mathrm{O}_{2}$ are initialized to zero (at midnight) and when only very small values of $\mathrm{HOCl}$ and $\mathrm{OClO}$ are retained. This is consistent with the low mixing ratio of OClO $(\sim 35 \mathrm{pptv}$ at 23 $\mathrm{km}$ ) derived from the AMON spectra. Thus, only the case with low chlorine activation allows us to reproduce the measurements with the box model. Under these conditions, inorganic chlorine is mainly partitioned between $\mathrm{ClONO}_{2}$ and $\mathrm{HCl}$.

No aerosols have been considered in the box model, since for all our simulations, an aerosol load similar to what was measured in the Arctic vortex in 1997 leads only to small $\mathrm{NO}_{2}$ variations over the period of our measurements ( 1 hour between ascent and occultation of LPMA, 5 hours between LPMA and AMON). Aerosols, however, do play a role for longer integration times in the absolute level of $\mathrm{NO}_{2}, \mathrm{HNO}_{3}$, and $\mathrm{ClONO}_{2}$ due to denoxification, denitrification, and heterogeneous conversion of $\mathrm{N}_{2} \mathrm{O}_{5}$ and $\mathrm{ClONO}_{2}$.

In Figure 2, we present the LPMA and AMON results for four altitudes together with the box model simulation producing the best fit with observations. As can be seen, the agreement of the box model calculations (assuming no aerosols) and the 


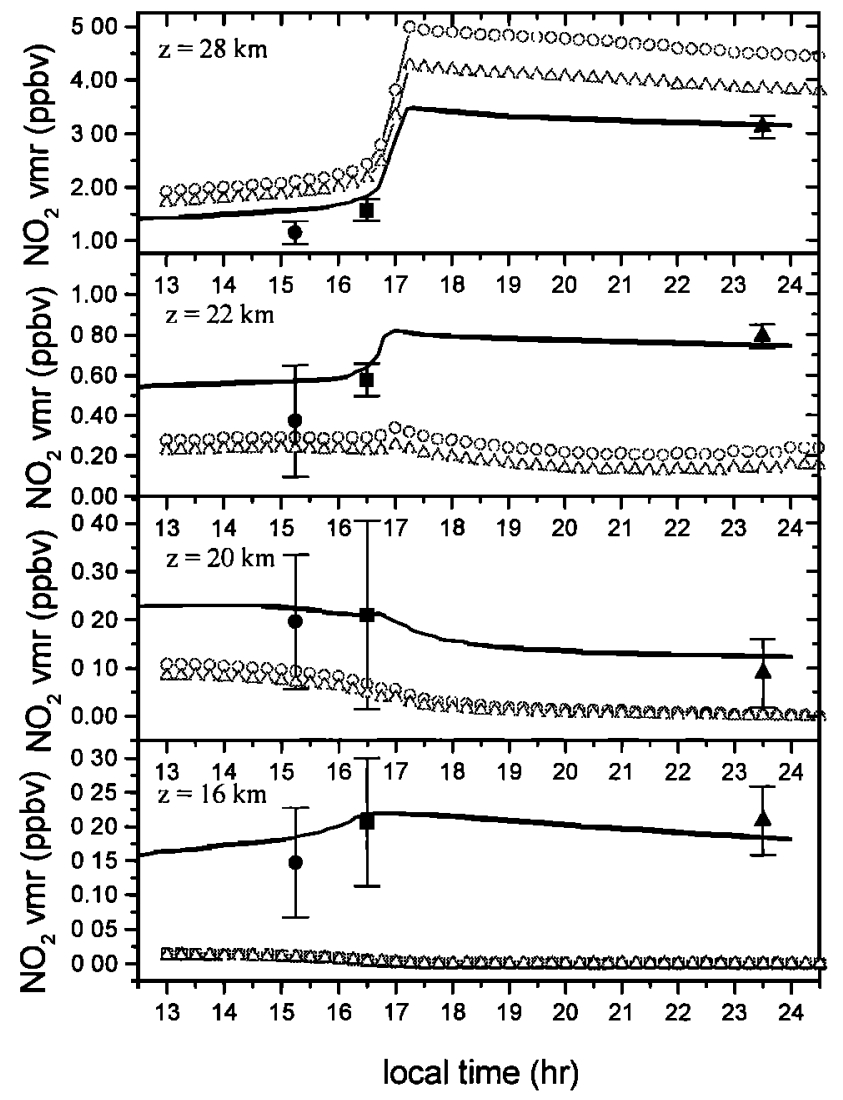

Figure 2. $\mathrm{NO}_{2}$ variation with time for the altitudes 16, 20, 22 and $28 \mathrm{~km}$ as predicted by a box model (black lines), by Reprobus with JPL97 (blue lines), and by Reprobus with updated rate constants (red lines). LPMA ascent measurements (boxes), LPMA occultation measurements (circles), and AMON measurements (triangles) are shown for comparison.

measurements for three different times of the diurnal/nocturnal cycle and for all the altitudes sampled by LPMA and AMON is rather satisfactory.

\section{Comparison With the Reprobus 3-D CTM Results}

The Reprobus model is a 3-D chemistry transport model which computes the time evolution of 55 stratospheric species [Lefevre et al., 1994; 1998]. The chemical package includes a comprehensive treatment of gas-phase chemistry (147 reactions and photolysis rates from JPL97 [De More et al., 1997]), as well as heterogeneous reactions taking place at the surface of liquid PSCs [Carslaw et al, 1995]. The model was initialized at the beginning of the winter. The wind and temperature fields used to drive the transport of chemical species and to compute the chemical rates have been prescribed every 6 hours by the ECMWF analysis and interpolated in time and space to match the Reprobus grid points. In this configuration, Reprobus extends on 31 vertical levels from the ground up to $10 \mathrm{hPa}$, with a horizontal resolution of $2^{\circ} \times 2^{\circ}$, and a chemical time step of $15 \mathrm{~min}$.

Figure 1 compares the $\mathrm{HCl}$ Reprobus profile interpolated in space at the location of the LPMA occultation measurements (i.e., $66.9^{\circ} \mathrm{N}, 19.8^{\circ} \mathrm{E}$ ). The model results show a significant $\mathrm{HCl}$ removal in the lower stratosphere, but not as large as suggested by the LPMA profile. However, it must be noted that the flight took place close to the edge of the polar vortex, in a region where the CTM indicates a latitudinal gradient. It can be seen that at $70^{\circ} \mathrm{N}$ (Figure 1), about 1 grid box farther north than the LPMA flight, the heterogeneous process was more substantial in the simulations. At this latitude the modeled $\mathrm{HCl}$ depletion is closer to what is observed in the LPMA profile. Let us recall that the partition between $\mathrm{HCl}$ and $\mathrm{ClONO}_{2}$ had been successfully modeled with Reprobus for a previous flight in the Arctic [Payan et al., 1998]. The fact that the chemically perturbed region is located in the model further north than in the observations also explains the overestimation of ozone seen above $20 \mathrm{~km}$ in Plate 2.

The comparison between $\mathrm{NO}_{2}$ measurements of LPMA at sunset, AMON at night, and Reprobus simulation is shown in Figure 3. Below $25 \mathrm{~km}, \mathrm{NO}_{2}$ is underestimated by Reprobus, whereas it is overestimated above as compared to LPMA and AMON measurements.

Plate 3 compares the $\mathrm{HNO}_{3}$ vertical profile measured by LPMA and ILAS and the corresponding Reprobus calculation. Between 17 and $23 \mathrm{~km}$, the model underestimates $\mathrm{HNO}_{3}$, whereas the opposite is observed outside this altitude range.

\section{Discussion}

The rapid time variation of $\mathrm{NO}_{2}$ prevents a direct comparison of the LPMA and AMON measurements and, as illustrated in

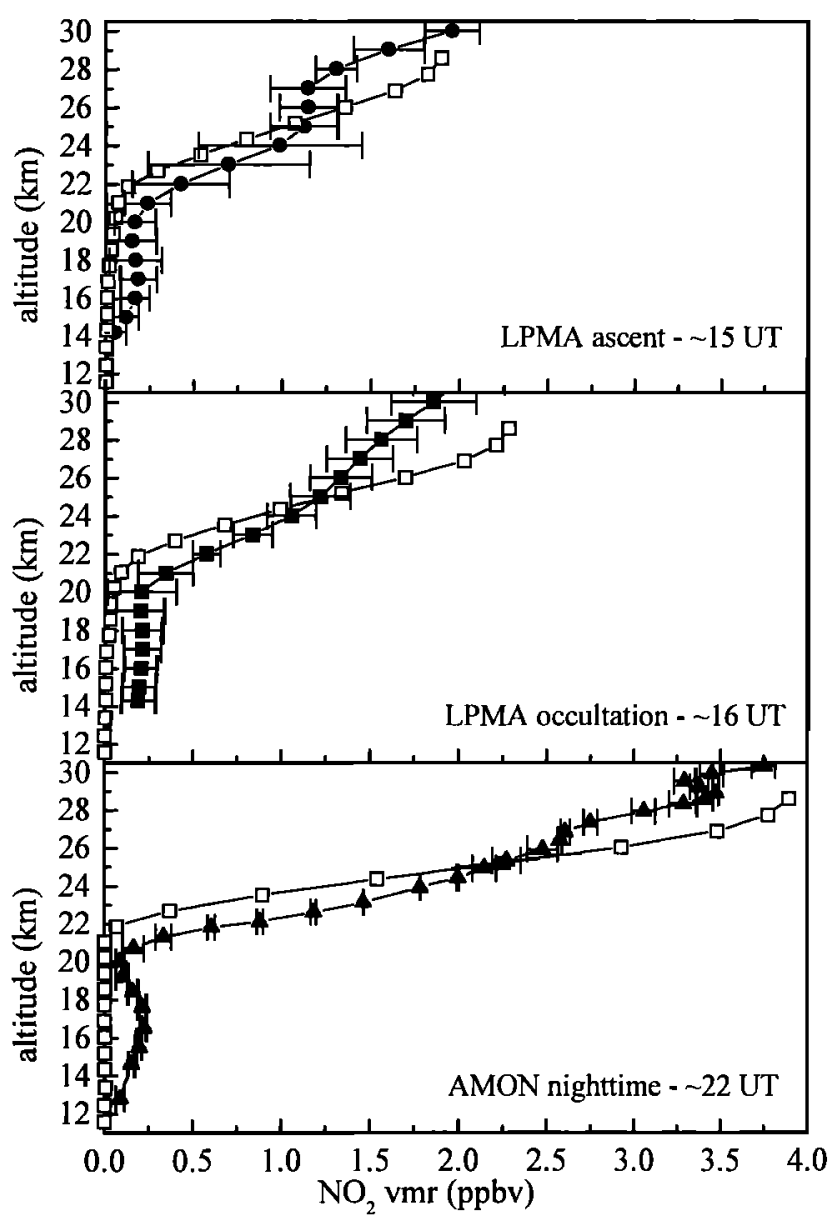

Figure 3. Comparison of $\mathrm{NO}_{2}$ Reprobus (JPL97 constants, open squares) with the measurements of LPMA during ascent (SZA = $83^{\circ}$, black boxes), LPMA during occultation (SZA $=90^{\circ}$, black circles), and AMON during the night (black triangles). 
Plate 1, the largest amounts of $\mathrm{NO}_{2}$ were recorded by AMON during the night when photodissociation is no longer active. But, using the box model with the constraints discussed above, the nighttime AMON measurements of $\mathrm{NO}_{2}$ have been converted back to the LPMA occultation measurement time. Figure 4 presents the converted $A M O N \mathrm{NO}_{2}$ profile and the occultation LPMA profile (corrected from photochemical effects, see section 2.1 above). It can be seen that the agreement between the two profiles is now particularly good (average difference less than 9\%). Small differences can be assigned to the insufficient knowledge of $\mathrm{J}_{\mathrm{NO2}}$ (R1) but also to uncertainties in the chemistry and/or to the partitioning of chlorine species discussed above. As illustrated in Figure 2, knowing the $\mathrm{NO}_{2}$ vmr for $\mathrm{SZA}=90^{\circ}$, our 24 hour box model integration is able to simulate the observed $\mathrm{NO}_{2}$ variation at any altitude during sunset and during the night, and to reproduce reasonably well the LPMA and AMON measurements. This is possible, however, with only a small degree of chlorine activation at initialization. This is not in agreement with the rather elevated Reprobus level of $\mathrm{ClO}(\sim 350$ pptv at $21 \mathrm{~km}$ ), an overestimation also contributing (through reaction (R7)) to the low values of $\mathrm{NO}_{2}$ calculated by the CTM below $25 \mathrm{~km}$.

The observed partitioning between $\mathrm{NO}_{2}$ and $\mathrm{HNO}_{3}$ is now compared to the seasonal CTM simulation taking into account stratospheric aerosols based on Stratospheric Aerosol and Gas Experiment (SAGE) II observations [Thomason et al., 1997] as well as the synoptic formation of PSCs according to the formulation of Carslaw et al.[1995]. The vertical distribution of the $\left[\mathrm{NO}_{2}\right] /\left[\mathrm{HNO}_{3}\right]$ ratio obtained from LPMA measurements and Reprobus shows a good agreement above $22 \mathrm{~km}$ (Figure 5), suggesting that the $\mathrm{NO}_{\mathrm{y}}$ partitioning is properly accounted for by the model in the middle stratosphere. Therefore the overestimation of $\mathrm{NO}_{2}$ by Reprobus above $25 \mathrm{~km}$ is probably explained by a too large $\mathrm{NO}_{\mathrm{y}}$ content at initialization and by the extrapolation of the $\mathrm{NO}_{\mathrm{y}}$ mixing ratios above the upper boundary of the model at $10 \mathrm{hPa}$ (i.e., around $29 \mathrm{~km}$ )

Below $22 \mathrm{~km}$, the $\left[\mathrm{NO}_{2}\right] /\left[\mathrm{HNO}_{3}\right]$ ratio calculated by the CTM is close to zero. This results from the complete heterogeneous conversion of $\mathrm{N}_{2} \mathrm{O}_{5}$ (the usual $\mathrm{NO}_{x}$ reservoir) into $\mathrm{HNO}_{3}$. The well-established probability value of 0.1 for this reaction [De

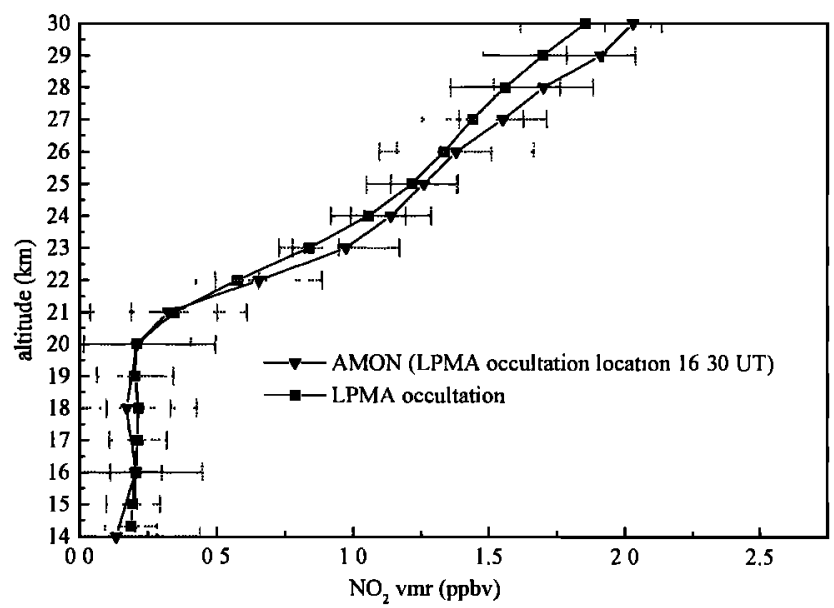

Figure 4. Comparison of $\mathrm{NO}_{2}$ LPMA occultation measurements (corrected from photochemical variation for $\mathrm{SZA}=90^{\circ}$ ) and AMON measurements converted to LPMA occultation time using a box model.

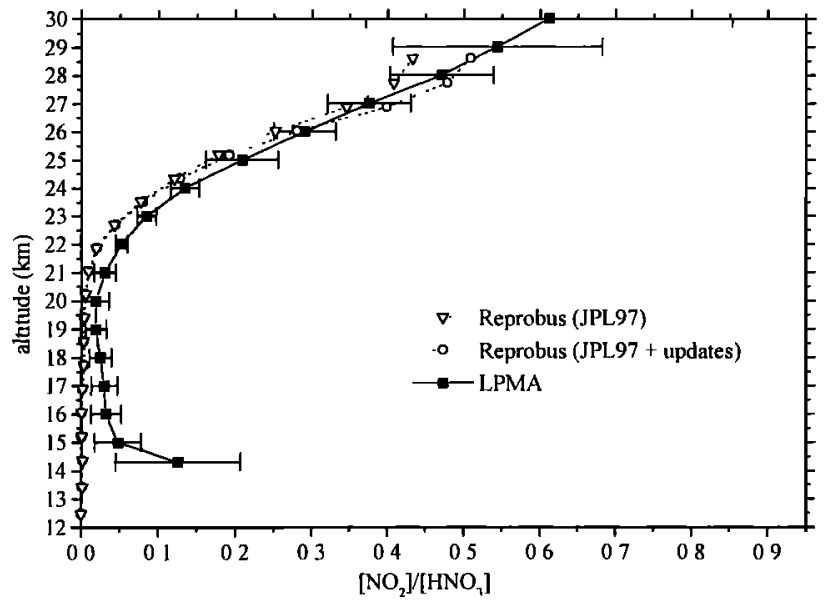

Figure 5. LPMA occultation measurements of the $\left[\mathrm{NO}_{2}\right] /\left[\mathrm{HNO}_{3}\right]$ ratio between 14 and $29 \mathrm{~km}$ (black boxes) compared to Reprobus modeling with JPL97 (open magenta squares) and with updated rate constants (open blue circles).

More et al., 1997] and the realistic aerosol distribution used suggest that another pathway to produce $\mathrm{NO}_{2}$ is lacking in the CTM.

The large amounts of $\mathrm{HNO}_{3}$ measured by LPMA and ILAS are a potentially significant source of $\mathrm{NO}_{2}$. The conversion in the CTM of a small amount of $\mathrm{HNO}_{3}$ into $\mathrm{NO}_{2}$ would not change significantly the $\mathrm{HNO}_{3} \mathrm{vmr}$ (within the error bars of the measurements; see Plate 3) while improving the agreement for $\mathrm{NO}_{2}$. As an example, the conversion of $0.4 \mathrm{ppbv}$ of $\mathrm{HNO}_{3}$ into $\mathrm{NO}_{2}$ would produce an exact agreement with LPMA at $22 \mathrm{~km}$ altitude and 1630 hours (see Figure 2) while also improving the agreement with $A M O N \mathrm{NO}_{2}$ at 2330 hours. Below $17 \mathrm{~km}$, the conversion of $\mathrm{HNO}_{3}$ into $\mathrm{NO}_{2}$ would improve the modeling of both $\mathrm{NO}_{2}$ and $\mathrm{HNO}_{3}$.

Although the model simulation indicates that $\mathrm{HNO}_{3}$ photolysis and its reaction with $\mathrm{OH}$ represent less than $5 \%$ of the total production of $\mathrm{NO}_{\mathrm{x}}$ below $28 \mathrm{~km}$ for $90^{\circ} \mathrm{SZA}$, uncertainties in the gas-phase chemistry could explain part of the $\mathrm{NO}_{\mathrm{x}}$ underestimation by the model [Sen et al., 1998]. Recently, the rate coefficients for $\mathrm{O}+\mathrm{NO}_{2}$ [Gierczak et al., 1999] and $\mathrm{OH}+$ $\mathrm{HNO}_{3}$ [Brown et al., 1999a] reactions were reported to be significantly higher than previously recommended, while the $\mathrm{OH}$ $+\mathrm{NO}_{2}$ reaction [Brown et al., 1999b] was found to be slower than reported by DeMore et al. [1997]. These updates in the gasphase chemistry, when implemented in Reprobus, do improve the results for $\mathrm{HNO}_{3}$ and the $\left[\mathrm{NO}_{2}\right] /\left[\mathrm{HNO}_{3}\right]$ ratio above $25 \mathrm{~km}$ (see Plates 3 and Figure 5), whereas they lead to very small changes below that altitude.

Alternatively, Lary et al. [1997] have suggested that heterogeneous processes occurring on the surface of carboneous soot particles may convert $\mathrm{HNO}_{3}$ to $\mathrm{NO}_{2}$. However, modeling studies [Aumont et al., 1999] suggest that, like the reaction $\mathrm{NO}_{2}$ + soot, the reaction $\mathrm{HNO}_{3}+$ soot may be slower than expected. Another reaction not included in Reprobus is the heterogeneous conversion of formaldehyde on $\mathrm{H}_{2} \mathrm{SO}_{4} / \mathrm{HNO}_{3} / \mathrm{H}_{2} \mathrm{O}$ aerosol, possibly leading to an additional conversion of $\mathrm{HNO}_{3}$ into $\mathrm{NO}_{2}$ in the stratosphere [Iraci and Tolbert, 1997]. Therefore the larger aerosol load at the lower altitudes could explain higher $\mathrm{NO}_{2}$ values if an additional heterogeneous reaction involving $\mathrm{HNO}_{3}$ to produce $\mathrm{NO}_{2}$ would be added in the model. If this process could act rapidly enough to compete with the different reactions 
resulting in a loss of $\mathrm{NO}_{2}$, it would offer an explanation for the underestimation of $\mathrm{NO}_{2}$ by the model below $22 \mathrm{~km}$.

\section{Conclusion}

We have presented new measurements of the $\mathrm{NO}_{2}$ vertical distribution performed on the same day (February 26, 1997) inside the polar Arctic vortex in late afternoon, at sunset and 5 hours later during the night using the balloon-borne instruments LPMA and AMON, in the framework of the ILAS validation balloon campaign in February 1997 from Kiruna, Sweden $\left(68^{\circ} \mathrm{N}\right.$, $21^{\circ} \mathrm{E}$ ). In addition, LPMA measurements of $\mathrm{O}_{3}, \mathrm{HCl}$, and $\mathrm{HNO}_{3}$ have been considered for comparison with models and to constrain them.

A 24 hour box model integration has been successfully used to scale the AMON nocturnal measurements to diurnal LPMA measurements. A noticeable dip is observed in the LPMA measured $\mathrm{HCl}$ profile, suggesting previous chlorine activation. However, in order to reproduce simultaneously the LPMA and AMON profiles, the box model has to be initialized with low $\mathrm{ClO}$ amounts, hence high $\mathrm{ClONO}_{2}$. This could be explained by the fast deactivation of chlorine species to $\mathrm{ClONO}_{2}$ buffering chlorine before final conversion to $\mathrm{HCl}$.

Comparisons of these results with seasonal Reprobus simulations show an underestimation of $\mathrm{NO}_{2}$ below $25 \mathrm{~km}$, during the day and during the night. In terms of $\mathrm{NO}_{\mathrm{y}}$ partitioning, the calculated $\left[\mathrm{NO}_{2}\right] /\left[\mathrm{HNO}_{3}\right]$ ratio is close to zero below $22 \mathrm{~km}$. This suggests that a possible source of $\mathrm{NO}_{2}$ is not included in the model. A change in the rate coefficients for the reaction $\mathrm{OH}+$ $\mathrm{HNO}_{3}$ [Brown et al., 1999a], when implemented in the chemical model, only slightly reduces the disagreement with the measurements and does not improve significantly the partitioning between $\mathrm{NO}_{2}$ and $\mathrm{HNO}_{3}$ below $22 \mathrm{~km}$. Thus, further laboratory studies are needed to quantify more precisely other possible processes converting $\mathrm{HNO}_{3}$ into $\mathrm{NO}_{2}$.

Even if global measurements of $\mathrm{NO}_{2}$ from space by the ILAS experiment are not yet fully reliable in the lower stratosphere (because they need improvement in the knowledge of the spectral dependence of the aerosol extinction coefficient), the $\mathrm{HNO}_{3}$ measurements by ILAS provide a particularly interesting source of data to improve the modeling of $\mathrm{HNO}_{3}$ and to test its possible contribution to the $\mathrm{NO}_{2}$ burden. The ILAS measurements of $\mathrm{O}_{3}$ also provide an interesting and extensive data set for the winter $1996 / 1997$ at high northern latitudes.

New simultaneous measurements of the full suite of $\mathrm{ClO}_{y}$ and $\mathrm{NO}_{\mathrm{y}}$ species are necessary to clarify the origin of the differences between model and observations, and a suite of dedicated balloon payloads to reach this objective is planned in the near future within several projects funded by the European Commission.

Acknowledgments. The LPMA and AMON flights were performed within the French Programme National de Chime Atmosphenque and with financial support from CNES and INSU The Geneva Observatory team lead by D. Huguenin is acknowledged for the LPMA and AMON gondola integration and pointing. The satellite data used were obtained with the Improved Limb Atmospheric Spectrometer (IAS) developed by the Environment Agency of Japan (EA) and on board the ADEOS, which was launched and operated by the National Space Development Agency of Japan (NASDA) These data were processed at the ILAS Data Handling Facility, National Institute for Environmental Studies (NIES).

\section{References}

Aumont, B., S Madronich, M. Ammann, M. Kalberer, U. Baltensperger, D. Hauglustaine, and F. Brocheton, On the $\mathrm{NO}_{2}+$ soot reaction in the atmosphere, J. Geophys. Res., 104, 1729-1736, 1999.
Brasseur, G, and S. Solomon, Aeronomy of the Middle Atmosphere, Atmos. Sci. Libr., 441 pp , D. Re1del, Norwell, Mass., 1986.

Brown, S S, R K Talukdar and A. R Ravishankara, Reconsideration of the rate constant for the reaction of hydroxyl radicals with nitric acid, $J$. Phys. Chem., in press, 1999a.

Brown, S S , R K Talukdar, and A.R. Ravishankara, Rate constants for the reactions $\mathrm{OH}+\mathrm{NO}_{2}+\mathrm{M} \rightarrow \mathrm{HNO}_{3}+\mathrm{M}$ under atmospheric conditions, Chem. Phys. Lett., 299, 277-284, 1999b.

Camy-Peyret, C., Balloon-borne Fourier transform spectroscopy for measurements of atmospheric trace gases, Spectrochim. Acta, 51A, $1143-1152,1995$

Carlotti, M, Global fit approach to the analysis of limb-scanning atmosphenc measurements, Appl. Opt., 27, 3250-3254, 1988

Carslaw, K. S., B Luo, and T. Peter, An analytic expression for the composition of aqueous $\mathrm{HNO}_{3}-\mathrm{H}_{2} \mathrm{SO}_{4}$ stratosphenc aerosols including gas phase removal of $\mathrm{HNO}_{3}$, Geophys. Res. Lett., 22, 1877-1880, 1995.

De More, W.B., S.P. Sander, D.M. Golden, R.F. Hampson, M.J. Kurylo, C.J Howard, A.R. Ravishankara, C.E. Kolb, and M.J. Molina, Chemical kinetics and photochemical data for use in stratospheric modeling, JPL Publ., 97-4, 266 pp , 1997.

Flaud, J.-M., C. Camy-Peyret, J.W. Brault, C.P Rinsland, and, D Cariolle, Nighttime and daytume variation of atmospheric $\mathrm{NO}_{2}$ from ground based infrared measurements, Geophys. Res. Lett., 15, 261264, 1988.

Gierczak T., J.B. Burkholder, and A.R. Ravishankara, Temperature dependent rate coefficient for the reaction $\mathrm{O}\left({ }^{3} \mathrm{P}\right)+\mathrm{NO}_{2} \rightarrow \mathrm{NO}+\mathrm{O}_{2}, J$. Phys. Chem., 103, 877-883, 1999.

Glatthor, N., C.E. Blom, T. von Clarmann, H. Fischer, T. Gulde, C. Piesch, F. Erle, K. Pfellsticker, M.P. Chipperfield, A.M. Lee, and J.A. Pyle, Aurborme remote sensing of $\mathrm{NO}_{2}$ in the Arctic winter of 1994 1995 and comparison with a three-dimensional chemical transport model, J. Geophys. Res., 103, 13315-13326, 1998.

Harder, J W., J W. Brault, P.V. Johnston, and G H. Mount, Temperature dependent $\mathrm{NO}_{2}$ cross sections at high spectral resolution, $J$. Geophys. Res, 102, 3861-3879, 1997.

Irac1, L.T and Tolbert M A., Heterogeneous interaction of formaldehyde with cold sulfuric acid: Implications for the upper troposphere and lower stratosphere. J. Geophys. Res., 102, 16099-16107, 1997.

Kanzawa, H., C. Camy-Peyret, Y Kondo, and N. Papineau, Implementation and first scientific results of the ILAS validation balloon campaign at Kiruna-Esrange in February-March 1997, Proc. $13^{\text {th }}$ ESA symposium on European rocket and balloon programs and related research, Eur. Space Agency Spec. Publ., SP 397, 211-215, 1997

Kerr, J.B., WF.L. Ewans, and J.C. McConnell, The effects of $\mathrm{NO}_{2}$ changes at twilight on tangent ray $\mathrm{NO}_{2}$ measurements, Geophys. Res. Lett., 14, 577-579, 1987.

Kondo, Y., T. Sugita, R.J. Salawitch, M Koike, and T. Deshler, The effect of Pinatubo aerosols on stratospheric NO, J. Geophys. Res., 102, 1205 1213,1997

Lary, D.J., R. Toumı, A M Lee, M. Newchurch, M. Pirre, and J.B Renard, Carbon aerosols and atmospheric photo-chemistry, 'J. Geophys. Res., 102, 3671-3682, 1997

Lefèvre, F., G. Brasseur, I. Folkins, A.K Smith, and P. Simon, Chemistry of the 1991-1992 stratospheric winter Three dimensional model simulations, J. Geophys. Res., 99, 8183-8195, 1994.

Lefèvre, F., F. Figarol, K.S Carslaw, and T. Peter, The 1997 Arctic ozone depletion quantified from three-dimensional model simulations, Geophys. Res. Lett., 25, 2425-2428, 1998

Naudet, J P., C. Robert, and D Huguenin, Balloon measurements of stratospheric trace species using a multichannel UV-Visible spectrometer, Proc $11^{\text {th }}$ ESA symposium on European rocket and balloon programs and related research, Eur. Space Agency Spec. Publ., $S P-355,165-168,1994$

Newchurch, M.J., et al, Stratospheric $\mathrm{NO}$ and $\mathrm{NO}_{2}$ abundances from ATMOS solar-occultation measurements, Geophys. Res. Lett., 23, 2373-2376, 1996

Payan S., C Camy-Peyret, P Jeseck, T. Hawat, G Durry and F. Lefève, First sumultaneous $\mathrm{HCl}$ and $\mathrm{ClONO}_{2}$ profile measurements in the Arctic vortex, Geophys. Res. Letters, 25, 2663-2666, 1998

Press, W.H., S.A. Teukolsky, W.T. Vetterling, and B.P. Flannery, Numerical recipes in Fortran, 2nd ed., 963 pp., Cambridge Univ. Press, New York, 1992.

Ramaroson, R.A., M Pirre, and D. Cariolle, A box model for one-line computations of diumal vanation in a 1-D model Potential for application in multidimensionnal cases, Ann. Geophys., 10, 416-428, 1992 
Renard, J.B, M Pirre, C Robert, D. Huguenin, G. Moreau, and J M. Russel, Noctumal distribution of stratospheric $\mathrm{O}_{3}, \mathrm{NO}_{2}$ and $\mathrm{NO}_{3}$ from balloon measurements, J. Geophys. Res., 101, 28793-28804, 1996.

Robert, C., Réalisation d'un spectromètre stellaire multicanal embarquable sous ballon stratosphérique, $\mathrm{Ph} . \mathrm{D}$ thesis, Univ. of Orléans, Orléans, 1992.

Russel, J.M., III, C.B. Farmer, C.P. Rinsland, R. Zander, L. Froidevaux G.C. Toon, B Gao, J Shaw, and M. Gunson, Measurements of odd nutrogen compounds in the stratosphere by ATMOS experiment on spacelab 3, J. Geophys. Res., 93, 1718-1736, 1988.

Sasano, Y, M. Suzuki, T. Yokota, and H. Kanzawa, Improved Limb Atmospheric Spectrometer (ILAS) for stratospheric ozone layer measurements by solar occultation technique, Geophys. Res. Lett., 26, 197-200, 1999

Sen, B, G.C Toon, G.B. Osterman, J.-F. Blavier, J.J. Margitan, R.J Salawitch, and G.K. Yue, Measurements of reactive nitrogen in the stratosphere, J. Geophys. Res., 103, 3571-3585, 1998.

Thomason, L.W., L.R. Poole, and T.R. Deshler, A global climatology of stratospheric aerosol surface area density as deduced from SAGE II: 1984-1994, J. Geophys. Res., 102, 8967-8976, 1997.

Webster, C.R., R.D. May, M. Allen, L. Jaegle, and M.P. MoCormick Balloon profiles of stratospheric $\mathrm{NO}_{2}$ and $\mathrm{HNO}_{3}$ for testing the heterogeneous hydrolysis of $\mathrm{N}_{2} \mathrm{O}_{3}$ on sulfate aerosols, Geophys. Res. Lett., 21, 53-56, 1994.

Wetzel, G., H. Oelhaf, T. von Clarmann, H. Fischer, F. Friedl-Vallon, G
Maucher, $M$ Seefeldner, and $O$ Trieschmann, Vertical profiles of $\mathrm{N}_{2} \mathrm{O}_{5}, \mathrm{HO}_{2} \mathrm{NO}_{2}$, and $\mathrm{NO}_{2}$ inside the Arctic vortex retrieved from nocturnal MIPAS-B2 infrared limb emission measurements in February 1995, J. Geophys. Res., 102, 19177-19186, 1997

Yokota, T., M. Suzuki, O.V Duvobik, and Y. Sasano, ILAS (Improved Limb Atmosphenc Spectrometer)/ADEOS data retrieval algorithms, Adv. Space Res., 21 (3), 393-396, 1998.

C. Camy-Peyret, P. Jeseck, and S. Payan, LPMA, UPMC/CNRS, 4 place Jussieu, Bte 76, 75252 Paris cedex 05, France. (payan@ccr.jussieu.fr)

T. Hawat, University of Balamand, Faculty of Engineering, P.O. Box 100 Tripolı, North Lebanon, Beirut, Lebanon. (hawat@ecr jussieu.fr)

H. Kanzawa, and Y. Sasano, National Institute for Environmental Studies, 16-2 Onogawa, Tsukuba, Japan (kanzawa@nies.go.jp)

F. Lefèvre, CNRS Service d'Aéronomie, Université Pierre et Marie Curie, BP 102, 4 Place Jussieu, 75252 Paris Cedex 05, France (franck.lefevre@gero.jussieu.fr)

M. Pirre, J.-B. Renard, and C Robert, LPCE-CNRS, 3A Avenue de la recherche scıentifique, 45071 Orléans cedex 2, France. (mpirre@cnrsorleans.fr)

(Received November 17, 1998; revised March 28, 1999; accepted April 20, 1999.) 